\title{
Amizade e emoções de rivalidade em Aristóteles: uma origem comum? ${ }^{1}$
}

\author{
Cristina Viano (Paris, C.N.R.S.)
}

As in Aristotle friendly feelings are often coupled with attitudes of rivalry, one may ask whether there is in the soul, according to Aristotle, a common origin for these apparently opposed emotions. A positive answer to this question will provide one with a better understanding of the Aristotelian notion of friendship, and, at the same time, with a deeper insight of the role thumos has in the Aristotelian moral psychology.

Em Aristóteles, o sentimento de amizade interage freqüentemente de modo surpreendente com as emoções competitivas como a cólera (orgê), a emulação (zêlos) e a rivalidade propriamente dita (philotimia), emoções que, como se pode constatar sobretudo na Retórica, constituem um dos pilares essenciais nas relações humanas.

Gostaria aqui de examinar a dialética destas interferências e de tentar responder à questão seguinte: há na alma, para Aristóteles, um ponto de origem comum para estas paixões aparentemente contraditórias, provenientes, de um lado, da amizade e, de outro, da rivalidade? Se a resposta for sim, esta origem comum nos permite compreender melhor a noção aristotélica de amizade?

1. A amizade e seus limites.

1 Este texto retoma e desenvolve uma investigação sobre os mecanismos e a origem das paixões de rivalidade. Cf. C. Viano, "Competitive emotions and the thumos in Aristotle's Rhetoric", in D. Konstan \& N. K. Rutter (eds.), Envy, Spite and Jealousy: The Rivalrous Emotions in ancient Greece, Edinburgh University Press (Edinburgh Leventis Studies I) 2003, p. 85-97, e "Passions, désirs et plaisirs de rivalité chez Aristote" in G. Romeyer-Dherbey-G. Aubry (éd.), L'Excellence de la vie. Sur L'Ethique à Nicomaque et l'Ethique à Eudème d'Aristote, Paris, Vrin 2002, p. 237252 (versão francesa mais extensa). 
Aristóteles analisa o tema da amizade em três lugares: na Ética Nicomaquéia VIII-IX, na Ética Eudêmia VII e na Retórica II 4.

Na Ética Nicomaquéia, Aristóteles distingue o sentimento de amizade (philêsis), que é um pathos, um estado emocional, e a amizade propriamente dita (philia), uma disposição permanente que tem por característica ser uma relação recíproca e ser acompanhada de uma escolha deliberada (VIII 7 1157b27). Nas Éticas, é a amizade neste sentido de disposição que é o tema, como o declara Aristóteles bem no início da Eth. Nic. VIII: "a amizade é, com efeito, certa virtude ou não ocorre sem virtude" (1 1155a1: esti gar aretê tis ê met'aretês).

Se, na Eth. Nic. II 4 1105b19, Aristóteles coloca a amizade entre as paixões ("entendo por paixões o apetite, a cólera, o medo, a audácia, a inveja, a alegria, a amizade, o ódio, o lamento, a emulação, a piedade, em suma tudo o que é seguido de prazer ou de dor"), não se deve esquecer que estas paixões são concebidas aqui como o terreno de aplicação do comportamento moral, visto que a virtude consiste justamente na atitude que se tem em relação às paixões: "entendo por disposições, enfim, nosso comportamento bom ou mau relativamente às paixões: por exemplo, para a cólera, se a sentimos forte ou fracamente, nosso comportamento é mau, ao passo que ele é bom se a sentimos com medida, e assim para as outras paixões". De fato, o sentimento de amizade é um pathos bom em si, que se manifesta em todos os seres vivos.

Nos logoi sobre a amizade das duas Éticas, nos quais Aristóteles disseca suas diferentes formas e circunstâncias, o focal meaning investigado é o de um bem moral. A amizade produz-se, em sua forma de excelência, entre os homens bons e se funda na virtude, distinguindo-se assim da amizade fundada no agradável e da amizade baseada no útil.

A análise da amizade na Retórica privilegia, por sua vez, o estado emocional. Neste contexto, as paixões humanas constituem ao mesmo tempo o objeto e o instrumento da persuasão. Em particular, tratando-se do gênero judiciário, Aristóteles analisa as paixões na dupla perspectiva dos móbiles do ato injusto (I 10) e dos meios técnicos para influenciar os juízes no tribunal (II 2-11). As paixões são definidas aqui como "as causas que fazem os homens variar alterando seus julgamentos ( $d i^{\prime}$ hosa metaballontes diapherousi pros tas kriseis) e têm por consequiências a dor e o prazer, como a cólera, a piedade, o medo e todas as outras emoções deste gênero, assim como seus contrários" (II 1 1378a19). Com efeito, em um processo, o estado emotivo de quem se pronuncia sobre a realidade de um delito e sobre seu grau de culpabilidade é fundamental: "pois as coisas não parecem as mesmas a quem ama ou a quem odeia (philousi kai misousi), a quem sente cólera ou a quem está em um habitus de calma" (II 
1 1377b31). Aristóteles desenvolve justamente neste tratado uma análise das paixões, ou melhor, uma retórica das paixões ${ }^{2}$ com o intuito explícito de trazer à luz tudo o que é persuasivo nos estados emotivos, em outros termos, de dar ao orador meios para agir eficazmente sobre o juízo do auditório. Assim, em II 4, o sentimento de amizade, bem como seu contrário, o ódio, são avaliados como estados emocionais persuasivos.

De fato, para além das diferentes intenções que animam as Éticas e a Retórica, Aristóteles nos fornece nestes contextos uma antropologia muito completa e realista da amizade. Mediante uma casuística detalhada, Aristóteles delimita os domínios de aplicação e, sobretudo, os limites teóricos e concretos deste sentimento social por excelência.

Quando se lê as páginas de Aristóteles sobre a amizade, percebe-se imediatamente que ela nada tem a ver com o altruísmo da moral judaico-cristã, na qual a afeição ao próximo não requer nada em troca. ${ }^{3}$ Em Aristóteles, não somente a afeição ao próximo exige a reciprocidade 4 , bem como toda uma série de condições psicológicas, morais e sociais de igualdade e de compensação, mas também a medida de toda forma de amizade, e portanto também da amizade kuriôs, é determinada por um sentimento originário profundamente individualista: o amor de si (philautia). Na Ética Nicomaquéia, Aristóteles dedica um capítulo inteiro (IX 8) à teorização do amor de si e de seu valor moral. Ele constata que se trata de um sentimento primordial, e portanto natural, que é anterior à amizade e que determina todos os sentimentos de afeição pelos outros. ${ }^{5}$ Aristóteles distingue dois sentidos que se atribui ao amor de si. O primeiro é

${ }^{2} C f$. P. Aubenque, "Logos et pathos. Pour une définition dialectique des passions (De anima, I, 1 et Rhétorique, II)", em Corps et âme. Sur le De anima d'Aristote, G. Romeyer-Dherbey e C. Viano (eds.), Paris, 1996, p. 7-49, aqui 46: “o que propõe o livro II não é portanto uma psicologia das paixões entendida como um requisito científico, mas uma retórica das paixões, suposta ser a única adequada a fornecer em argumentos um discurso retórico destinado a agir sobre a afetividade".

3 Para a diferença entre a moral grega e a concepção moral judaico-cristã, a qual, implicando o amor incondicional por Deus e os outros homens, exclui a rivalidade como bem, ver as reflexões de Ch. Gill, «Is rivalry a virtue or a vice?» in D. Konstan - K. Rutter (eds.), Envy, Spite and Jealousy, op. cit. p. 29-51, em particular p. 31.

${ }^{4}$ Cf. a definição da Retórica II 4, 1380b 35: "admitamos portanto que amar (philein) é desejar para alguém o que se acredita ser bens, para ele e não para nós, e também estar, na medida de seu poder, inclinado a fazer estes bens. É nosso amigo quem nos ama e a quem amamos em troca (philos de estin ho philôn kai antiphiloumenos). Se tomam por amigos os que estão nesta disposição um com o outro (pros allêlous)". Cf. Eth. Nic. VIII 7 1157b27.

5 Cf. Eth. Nic. IX 8, 1168 b 9: "partindo desta relação de si mesmo a si mesmo, todos os sentimentos que constituem a amizade se aplicam em seqüência aos outros homens ( $a p^{\prime}$ autou panta ta phusika kai pros tous allous diêkei)". 
negativo e reflete a opinião da turba: ele designa quem toma para si todos os bens (riquezas, honras e prazeres corporais) que são objeto de disputa (cf. perimachêta, 1168 b15) entre os homens. O segundo é positivo e designa quem atribui a si o melhor obedecendo à parte mais nobre de si. É justamente neste sentido, conclui Aristóteles, que o homem bom deve ser egoísta, "pois ele tirará proveito ao praticar o bem e fará ao mesmo tempo com que os outros dele se beneficiem" (1169a12-13). Note-se que, nesta definição do "bom" egoísmo, o componente de auto-afirmação persiste e muda o fim que é o bem.

O amor de si (philautia) determina assim ao mesmo tempo a medida e os limites da amizade. Se o amigo é concebido como um outro eu, é justamente o eu que limita o élan da amizade. De que maneira? Vejamos alguns exemplos. Na Eth. Nic. VIII 9 1159a5, Aristóteles indaga se, afinal de contas, os amigos desejam verdadeiramente os maiores bens para seus amigos, como, por exemplo, ser deus, pois, então, não seriam mais seus amigos, nem por conseguinte bens, pois os amigos são bens. Aristóteles conclui que os bens que se desejam aos amigos devem ser os que os deixam tais como já são. Ele acrescenta que, se o amigo deseja bens ao amigo, talvez não sejam, no entanto, todos os bens, haja vista a que cada um deseja ter os bens principalmente para si próprio (1159a11). Na Rhet. II 4, quando esboça a tipologia dos amigos potenciais, Aristóteles precisa os limites entre a partilha e a rivalidade: "(amamos com amizade) os que se assemelham a nós e têm as mesmas ocupações que nós (kai tous homoious kai tauta epitêdeuontas), desde que não nos atrapalhem e não tenham os mesmos meios de existência, pois, neste caso, 'o ceramista faz concorrência ao ceramista" (1381b14); "os que têm os mesmos desejos (kai tous tôn autôn epithumountas) que nós, desde que nos seja possível participar das mesmas vantagens; caso contrário, o resultado é o mesmo que no caso precedente" (1381b17); "aqueles a quem ajudamos a obter os bens que desejam, se não resultar para nós males maiores" (1381b23).

Estas passagens mostram de modo claro que a igualdade e a semelhança sobre as quais se funda a amizade estão também na origem da rivalidade quando a partilha dos bens desejados se revela impossível ou forçosamente unilateral. Ademais, note-se que não somente o desequilíbrio entre as vantagens acarreta necessariamente a concorrência, mas também que a tendência natural de todos os homens é de atribuir a si os bens maiores antes que os desejar ao seu próximo.

2. Amizade, cólera e emulação. 
No contexto simultaneamente social e jurídico da Retórica, os estados emocionais de agressividade e de rivalidade têm um papel decisivo e aparecem como um elemento essencial nas relações humanas. Ora, o sentimento de amizade interage com duas emoções de rivalidade fundamentais: a cólera e a emulação.

A cólera (orgê) é a paixão abordada primeira e mais longamente na Retórica; ela constitui freqüentemente em Aristóteles o exemplo paradigmático da paixão enquanto tal. Assim a define Aristóteles:

Admitamos que a cólera seja um desejo doloroso de vingança notória provocado por um desdém notório pela nossa pessoa ou pela dos nossos, este desdém não sendo merecido (estô dê orgê orexis meta lupês timôrias phainomenês dia phainomenên oligôrian tôn eis auton ê tôn autou, tou oligôrein mê prosêkontos). Se a cóleras consiste bem nisso, segue-se necessariamente, primeiramente, que a pessoa se põe sempre em cólera contra um indivíduo determinado, por exemplo Cleon, e não contra o homem em geral; em seguida, que foi feita ou que se quis fazer contra nós mesmos ou contra um dos nossos uma ação determinada; em terceiro lugar, que a todo movimento de cólera é consecutivo um prazer (pasê orgê hepesthai tina hêdonên) devido à esperança de se vingar. (Rhet. II 2 1378a30-b 1)

A cólera aparece claramente aqui como uma emoção "reativa", sobretudo a esta forma de provocação que é um desdém 6 manifesto. O desdém é uma opinião que atribui pouco valor a algo (peri to mêdenos axion). Nas relações humanas, negar publicamente o valor de alguém significa afirmar sua inferioridade e pôr em crise sua posição na sociedade. A descrição dos habitus favoráveis à cólera (quando se está enfermo, em guerra, amando, sedento, em geral possuído por um desejo que não se logra satisfazer) mostra que esta reação nasce essencialmente quando se é contrariado (cf. os verbos: antikrouô, antiprattô, mê sumprattô) em um desejo ou em uma ação. Observar-se-á que os desejos insatisfeitos de que se trata são designados em geral como apetites (holôs epithumountes) e podem dizer respeito também a impulsos puramente físicos, como a sede e o amor físico (erôta). Aristóteles mostra bem aqui a interação destes estados emocionais com a cólera: é dito que os primeiros abrem caminho

6 As variedades do desdém (kataphronêsis) são: desprezo (oligôria), vexação (epêreasmos), insulto (hubris), desrespeito (atimia, que é uma forma de insulto). O insulto e o desrespeito merecem uma atenção especial. O insulto consiste em atos ou frases que podem fazer sentir vergonha (aischunê) a alguém no simples intuito de sue próprio prazer. A vergonha é definida mais adiante $(6$ 1383b12) como "uma dor ou uma perturbação relativa aos vícios presentes, passados ou futuros que parecem implicar a perda da reputação (eis adoxian)". Na Ética Nicomaquéia IV 15, Aristóteles considera o pudor (aidôs), assim como a vergonha (aischunê) como paixões e não virtudes. Há, portanto, estados médios nas paixões; o justo pudor, ainda que não seja uma virtude, é contudo louvável ( $c f$. II 7 1108a30). 
(proodopoieitai) à última (1379a21). A pacificação da cólera que se segue à vingança é a calma (praotês), que consiste em uma volta ao estado normal.

A cólera aparece assim ao final desta análise como um estado emocional agressivo por reação, visto ser a resposta a uma provocação. Pierre Aubenque, em seu célebre artigo "Sobre a definição aristotélica da cólera", designa este fenômeno como uma "contestação de troco": dado que o desprezo consiste no duplo movimento de contestação da existência do outro e de atestação de sua própria existência como superiora, a cólera contesta, por sua vez, a existência do outro e, deste modo, reafirma sua própria existência. ${ }^{7}$

Voltemos agora à interação com a amizade. Nota-se que, conforme à definição acima, a cólera se volta tanto contra quem nos ofendeu quanto contra quem ofendeu algum dos "nossos". Nesta perspectiva, a pessoa próxima, objeto de nossa afeição, é considerada como um outro eu. Por conseguinte, toda ofensa que lhe é dirigida desencadeia em nós uma reação igual à desencadeada por uma ofensa dirigida diretamente contra a nossa pessoa. Os amigos podem também provocar a cólera, e de modo muito intenso. Aristóteles lista os seguintes casos: “(põe-se em cólera) contra os que são amigos mais do que contra os que não o são, pois se crê ter o direito de ser antes bem do que mal tratado por eles (oiontai gar prosêkein mallon paschein eu hup' autôn $\hat{e}$ $m \hat{e})$ " (1379b2); "contra nossos amigos se eles não falam e não agem bem para conosco, e ainda mais se falam e agem mal em relação a nós; se não se dão conta de nossas necessidades (...); não se dar conta é, com efeito, um índice de desdém (oligôrias), pois aquilo de que nos ocupamos não nos passa despercebido" (1379b13); "contra quem fica indiferente ante o relato ou o espetáculo de nossas fraquezas, pois são semelhantes a indiferentes ou a inimigos; a amizade, com efeito, toma parte na dor dos amigos e o espetáculo de seus próprios defeitos é penoso a todos os homens" (1379b20).

Compreende-se que, em todos estes casos, a cólera é a conseqüência de uma dupla provocação: a ofensa em si e a decepção que provém da identificação do provocador a um amigo, decepção que se pode ligar ao princípio geral segundo o qual se sente cólera quando se espera o contrário do que ocorre (1379a25). A razão fundamental da intensificação da cólera nesta situação parece explicada, em última instância, nos termos quantitativos de uma dupla injustiça: o desdém imerecido, portanto injusto, e a atitude injusta do amigo.

7 P. Aubenque, "Sur la définition aristotélicienne de la colère", Revue philosophique (147, 1957), p. 300-317, aqui p. 307-310. 
A outra paixão competitiva com a qual interfere a amizade de modo ainda mais direto é a emulação. A emulação (zêlos) (II 11) constitui, com a inveja (phthonos) (II 10), um par de paixões competitivas por excelência. Estamos aqui ainda em presença de um mecanismo emotivo de reação, não mais a uma provocação direta, como a cólera, mas a um estado de coisas que privilegia outro indivíduo. A emulação consiste em uma dor suscitada pela posse manifesta de bens estimados por parte de nossos pares, mas a dor incide sobre o fato que não possuímos também estes bens, dos quais nos consideramos dignos, e não porque estes bens pertencem a outro, como no caso da inveja. Eis porque se trata de uma paixão honesta (epieikes), enquanto a inveja é uma paixão moralmente negativa (phaulon). ${ }^{8}$ Os bens estimados (entima agatha), que são objeto da emulação, adquiridos por indivíduos moralmente positivos, são úteis e bons para a comunidade dos homens. Entre estes bens, contam-se a coragem, o saber e o comando (andria, sophia, archê, 1388b16).

No contexto específico da análise da amizade (II 4), Aristóteles diz explicitamente que "aqueles de quem somos rivais (pros hous philotimountai) ou de quem desejamos excitar a emulação, mas não a inveja, nós os amamos ou desejamos ser seus amigos" (toutous ê philousin ê boulontai philoi einai, 1381b21). Entre as questões principais das emoções rivais honestas, como a emulação, se encontram, como vimos, a posse de bens dignos (entima agatha), mas também a honra (timê) e a boa reputação (eudoxia). Na verdade, embora não the dedique uma análise específica na Retórica, Aristóteles liga a paixão de "rivalidade" propriamente dita, a philotimia (literalmente "amor pelas honras"), a todos os fenômenos emotivos de agressividade e de competição: os philotimoi são os mais inclinados à vitória, à competição, ao comando, à cólera, à inveja, à emulação. Compreende-se assim a razão da dupla tradução de philotimia por "ambição" e "rivalidade": a ambição se exprime essencialmente como rivalidade.

Porém, se a philotimia é compartilhada, em diferentes graus de intensidade, por todos os homens, Aristóteles postula na alma humana um outro desejo ainda mais original, que parece estar ligado a todas as formas de rivalidade, o sentimento de superioridade (huperochê): "vencer é agradável não somente para os ambiciosos (philotimoi), mas para todo mundo, pois se produz uma imaginação de

8 Na Eth. Nic. II 71108 b1 ss., o phthonos é uma das paixões extremas que dizem respeito aoprazer e à dor que se sente em relação ao que ocorre com outros. O justo meio entre a inveja e a malevolência (epichairekakia) é a justa indignação (nemesis), que não é uma virtude, mas faz parte dos justos meios nas paixões, assim como o pudor. Não temos aqui traços da emulação (zêlos). A propósito, na Ética Nicomaquéa, este termo aparece somente na lista das paixões em II 41105 b19 ss. e não é objeto de uma análise específica. 
Journal of Ancient Philosophy Vol. II 2008 Issue 1

superioridade (phantasia gar huperochês gignetai), da qual todos os homens têm um desejo mais ou menos forte" (Rhet. I 11 1370b32). O prazer ligado à esperança da vitória explica, por sua vez, o prazer que sentimos em atividades competitivas como os jogos, a caça, as batalhas, as disputas, a luta e a erística. O sentimento de superioridade não parece estar ligado somente ao desejo de vitória, mas parece também estar na origem da reação de cólera o desrespeito, o qual é sempre uma diminuição. Tem, pois, relação com o sentimento de amizade. Com efeito, em Eth. Nic. VIII 8 1158b11, Aristóteles menciona a forma de amizade (philia) fundada na superioridade ( $k a t h^{\prime}$ huperochên), como a que existe entre pai e filho ou governante e subordinado.

Vimos que o amor de si, a forma original e primordial do philein, visa, em sua forma trivial, a atribuir-se todos os bens que são habitualmente objeto de disputa entre os homens, como as riquezas ou as honras (cf. timai, Eth. Nic. IX 8 1168b15). Haja vista a estes elos estreitos entre amizade e rivalidade, desejo de superioridade e amor de si, pode-se postular que existe na alma uma origem comum destes estados emocionais à primeira vista tão contraditórios? Na Ética Niocmaquéia, Aristóteles explica que as paixões se distinguem e dependem das faculdades da alma que lhes correspondem segundo uma relação de potência e ato: "chamo faculdades (dunameis) estas coisas pelas quais somos capazes de experimentar estas paixões (kath' has pathêtikoi toutôn)" (II 4 1105b23). Nesta perspectiva, podemos então nos perguntar: há uma faculdade da alma que preside ao mesmo tempo as emoções de amizade e de rivalidade?

\section{O thumos poiôn to philêtikon}

Aristóteles nos dá a resposta em uma célebre passagem da Política. Em VII, Aristóteles descreve os caracteres das populações que vivem em diferentes latitudes como dominados por vezes pela coragem, por vezes pela inteligência. Somente a raça dos Helenos, que ocupa uma posição geográfica intermediária, se distingue por uma mistura feliz destas duas virtudes. A mesma diferença entre natureza unilateral e feliz mistura se encontra entre os próprios gregos, o que leva Aristóteles a concluir: "é portanto manifesto que são os que são ao mesmo tempo inteligentes e corajosos que poderão deixar-se conduzir à virtude pelo legislador" (dei dianoêtikous te einai kai thumoeideis tên phusin, 1327b36). Em seqüência, Aristóteles evoca a descrição do 
caráter thumoeides dos guardiães da República platônica. ${ }^{9}$ Vale a pena reproduzir a passagem em sua integralidade:

O que, pois, no dizer de alguns (cf. Resp. II 375 b-d), deve caracterizar os guardiães, a saber, ser amáveis em relação aos que conhecem e rudes em relação aos que não conhecem, é, na verdade, o thumos ${ }^{10}$ que está na origem da afetividade, pois é a faculdade da alma pela qual nós amamos. Uma prova disso é que o thumos se rebela mais contra os amigos e os conhecidos do que contra os desconhecidos, quando se crê desdenhado por eles. Eis por que Arquíloco, reclamando de seus amigos, diz com muita propriedade a seu thumos:

"Pois a ti, por certo, teus amigos te sufocam";

E o sentimento de comando e o de liberdade derivam também, em todos os homens, desta faculdade, pois o thumos é autoritário e indomável. Porém, é um erro descrever os guardiães como rudes em relação aos que não conhecem ( $c f$. Resp. II 375 c e ss.), pois não se o deve ser em relação a ninguém, e os homens de uma natureza magnânima não o são, a não ser em relação aos que cometem injustiças. Experimentam tais sentimentos mais contra os conhecidos, assim como dissemos acima, se crêem ter sofrido uma injustiça de sua parte. Trata-se de um sentimento legítimo, pois pensam que, além do dano sofrido, são privados do reconhecimento de pessoas que, eles estimam, lhes o deviam. De onde estas palavras:

"Cruéis são as guerras entre os irmãos" 11

ou ainda:

"Quem ama com excesso odeia com excesso".12

9 Aubonnet (Aristote, Politique, texto est. e trad. por J. A., Paris, 1960-86, t. III, p. 177) considera estas observações sobre o caráter natural dos cidadãos (1327b19-31) e sobre o thumos dos guardiães (1327b38 ss.) como dois apêndices extraídos dos diálogos de Aristóteles e acrescentados sucessivamente. Aubonnet supunha que a Urpolitik de Aristóteles fosse constituída por uma versão antiga dos livros "platonizantes", os VII e VIII. Ver sobre este ponto P. Pellegrin, Aristote, Les Politiques, Paris 1993, intr. pp. 65-66.

10 Os tradutores franceses (Aubonnet, Tricot, Pellegrin) traduzem o termo thumos desta passagem pelo termo homérico "coração" por conta de seu elo com a afetividade. Prefiro manter pelo momento o termo grego para designar a faculdade impulsiva que está aqui em questão. Para as diferentes traduções de thumos em Aristóteles, $c f$. A. Wartelle, Lexique de la Rhétorique d'Aristote, Paris 1982, s.v. thumos: "Volonté, cœur, désir, colère, ardeur, emportement" <vontade, coração, desejo, cólera, arrebatamento>.

11 Eurípides, fr. 975 Nauck.

12 Pol. VII 7 1327b39-1328 a 16: oper gav fasivtine" deih uparcein toi" fulvaxi, to; fil ht ikou," men eihai twh gnwrimwn pro," de; tou," agnwta " agriou", ol qumou eśt in of poiwh to; il htikon: aufh gar eśtin hJth" yuch" dumami" h/f iloumen. shmeibn dev pro," gar tou," sunhqei" kai; fivou" ol qumo," aifetai mall on h]pro," tou," aǵnwta", oligwreisqai nomisa". dio; kai; A rcivoco" proshkontw" toi" fivoi" egkalwh dialegetai pro", ton qumon: suigar dh;para;f ilwn apagceaif kai; $0 ; a$ lc con de;kai; 
Podem-se distinguir nesta passagem duas partes distintas:

(1) (1327b39- 1328a8): Aristóteles refere-se positivamente à teoria platônica de Resp. II 375 c ss. segundo a qual o caráter dos guardiães deve ser ao mesmo tempo afável em relação aos amigos e rude (agrios) ${ }^{13}$ em relação a desconhecidos. Aristóteles explica isso designando explicitamente o thumos simultaneamente como a faculdade impulsiva, a sede reconhecida da agressividade e como a sede da afeição. Aduz como prova (sêmeion) disso o fato que a pessoa se põe mais em cólera contra os amigos do que contra os inimigos quando se crê objeto de desdém. Em seguida Aristóteles retorna às características agressivas do thumos e parafraseia Platão para confirmar que o thumos é também a sede do desejo de comandar e de ser livre. ${ }^{14}$ No que tange à liberdade, vimos que, com efeito, a cólera é uma reação ao que nos contraria em nossos desejos ou em nossas ações. O thumos reage aos entraves. Na passagem da República em questão, Platão se refere à aporia da possibilidade da existência de uma natureza que possa apresentar ao mesmo tempo duas características opostas: a mansuetude e a agressividade. ${ }^{15} \mathrm{O}$ problema se generaliza e diz respeito à possibilidade de uma natureza que apresente contrários. A solução provém da observação dos cachorros de boa raça, que são ao mesmo tempo agressivos com os desconhecidos e calmos com as pessoas conhecidas. ${ }^{16}$ Porém, isso implica que se sabe distinguir um rosto amigo de um

to;el euger on apo;th" dunamew" tauth" uparcei pasin: ajcikongar kai;ahtthton ol qumo". oujkal w" dækei legein cal epou," eihai pro," tou," agnwta": pro," ougena gar eihai crh; toiout on, oudeveisin oil megal oy uc oi thn fusin agrioi, plhn pro," tou," adikounta". touto de; mallon ef i pro," tou," sunhqei" pascousin, oper eithtai proteron, ah adikeisqai nomiswsin. kai; tout o sumbainei kata; logon: par joil gar of eivesqai dein thn euergesian upol ambanousi, pro," twy blabei kai; t auth" apostereis qai nomizous in: ofjen eifhtai teal epoi; polvemoi gar adelf whEkai; tei \{toi pera/s terxante", oi le kai; pera/mis ous infE

13 Na Eth. Nic. IV $141128 \mathrm{a} 9$ e b2, agrios é sinônimo de sklêros (duro), chalepos (difícil), orgilos (colérico). Em Hist. Anim. IX 44 629b7, agriotês é oposto a praotês, a mansuetude, que é o justo meio na cólera.

14 Cf. Platão, Resp. 375a10: "poderia ser corajoso (andreios) um cavalo ou um cachorro, ou qualquer outro animal que não seja irascível (thumoeidês)? Você não pensa que o thumos é algo de indomável e invencível, por cuja presença toda alma é intrépida e imbatível em cada coisa?" (amachon te kai akinêton thumos, hou parontos psuchê pasa pros panta aphobos te esti kai aêttêtos;).

15 "O problema se põe: como os guardiães poderão ser ao mesmo tempo afáveis com os familiares e agressivos com os inimigos?" (pros men tous oikeious praous autous einai, pros de tous polemious chalepous) (375 c 1$)$.

16 Os intérpretes desta passagem (Aubonnet, Laurenti, Newmann) viram nesta comparação uma alusão a Heráclito B 97: "os cachorros latem até contra quem eles não identificam”. 
rosto desconhecido. Platão conclui que a natureza dos guardiães deve ser ao mesmo tempo irascível e filosófica, pois saber distinguir uma visão amiga de uma visão inimiga, o familiar do estrangeiro, provém do amor do conhecimento (376 b).

(2) (1328 a 8-16): Aristóteles critica a parte da tese platônica segundo a qual os guardiães devem ser duros com os desconhecidos, pois isto é contrário a uma natureza magnânima. ${ }^{17} \mathrm{O}$ homem altivo ou magnânimo é duro unicamente com quem comete uma injustiça.

Ora, Aristóteles não critica a questão posta por Platão a propósito do fato de a natureza da alma poder suportar os contrários 18 (mansuetude e agressividade), mas o princípio político (e moral) segundo o qual é preciso ser rude com os desconhecidos, opondo-lhe o princípio ético geral que se deve ser magnânimo em relação a todos os seres humanos. Aristóteles evoca, no entanto, a justa cólera do homem magnânimo em relação à injustiça, principalmente o caso específico de uma injustiça cometida por amigos. Aristóteles nos oferece então uma explicação "quantitativa" do sentimento legítimo (kata logon) de cólera sentida nesta situação: ao dano da própria injustiça se acrescenta a privação do retorno da beneficência que estendemos aos nossos amigos. $\mathrm{O}$ termo empregado é euergeia, "fazer o bem", o que exprime a manifestação por excelência da amizade. ${ }^{19}$

17 A altivez ou magnanimidade (megalopsuchia) é a dignidade da pessoa e o justo sentimento de seu próprio mérito (cf. Eth. Nic. IV 7-9). O homem magnânimo é quem se considera digno de grandes coisas e ele de fato o é (IV 7 1123b9).

18 Vestígios de debates acadêmicos sobre os contrários na alma se encontram nos Tópicos. Em II 7 113a33-b6, encontramos em particular a atribuição da cólera e da philia à parte thumoeides da alma: "ademais, se o acidente que foi posto possui um contrário, ver se o sujeito é suscetível de receber este contrário assim como ele o é de receber o próprio acidente, pois é sempre um mesmo sujeito que é suscetível de receber atributos contrários. Se o adversário sustenta, por exemplo, que a cólera implica o ódio, o ódio deveria ter por sede a parte irascível da alma (en tô thumoeidei), pois é aí que reside a cólera. É preciso, portanto, ver se o contrário do ódio reside também nesta parte irascível, pois se isso não for o caso e se é na parte concupiscível que reside o amor (philia), a cólera não poderia implicar o ódio. Mesma fórmula se o adversário sustenta que a parte concupiscível da alma é ignorante: ele deveria, com efeito, ser suscetível de saber, se fosse suscetível de ser ignorante; ora, que a parte concupiscível seja suscetível de saber não é o que se admite. $C f$. também IV 5 126a6.

19 Na Eth. Nic. VII 1 1155a6, Aristóteles diz que são sobretudo os homens ricos, responsáveis e poderosos que têm necessidade de amigos: "a quem serviria uma tal prosperidade quando não houver a possibilidade de fazer o bem (aphairetheisês euergesias) aos outros, a qual se manifesta principalmente e de modo mais digno de elogio em relação aos amigos?". 
Esta passagem da Política é crucial para nossos propósitos, e isto por três razões: (a) Aristóteles liga aqui expressamente o pathos da afetividade ao thumos, a faculdade impulsiva que preside tanto a cólera quanto o sentido de comando e de liberdade; (b) ele fornece ao mesmo tempo uma explicação psicológica e uma justificação ética da interferência entre cólera e amizade no caso de uma injustiça infligida por um amigo; (c) ademais, mediante a crítica da tese de Platão, Aristóteles suscita a questão da presença de paixões contrárias na alma, como o sentimento de afeição e de cólera.

Por que, porém, o fato de nos pormos mais em cólera contra os amigos que nos fizeram uma injustiça do que contra inimigos constitui uma prova, ou melhor: um sinal que o sentimento de amizade e a cólera dependem da mesma faculdade, a saber, o thumos? Poder-se-ia supor que é porque se trata de uma espécie de cólera que implica analiticamente um sentimento prévio de afeição pelas mesmas pessoas que nos ofenderam. Neste caso, as duas paixões contrárias, afeição e irritação, não são realmente simultâneas, mas sucessivas. Por outro lado, no que toca à presença de rivalidade e amizade na emulação, pode-se supor que se trata de duas paixões contrárias simultaneamente em ato. De fato, neste caso, não se trata de duas paixões radicalmente opostas, como no caso precedente. Estamos aqui no domínio de paixões completamente dominadas pela virtude, que tendem todas ao mesmo fim: o bem, o kalon.

No entanto, para voltar ao caso específico da cólera contra os amigos, a explicação acima não nos diz, de maneira suficiente, qual é, no nível do thumos, o verdadeiro elo que subsiste entre afeição e irritação. Dito de outro modo, Aristóteles não nos dá nunca uma descrição do desejo impulsivo, do thumos, que nos mostre o que há de comum entre a afetividade e a hostilidade. Em sua passagem da Política, Aristóteles apresenta o caso da intensidade da cólera contra os amigos que nos enganam como um sinal (sêmeion) que o thumos é também a função de afetividade. Porém, um sinal não mostra nada de necessário nem estabelece relações de causa: limita-se a mostrar um elo, uma concomitância. Em nosso caso, ele mostra que, em certa situação, os estados emocionais de afeição e de cólera interagem e dizem respeito aos mesmos sujeitos. ${ }^{20}$

Uma tentativa de oferecer uma definição global de thumos, que possa implicar todas as suas manifestações passionais, inclusive a afeição, foi feita por P. Meyer em um ensaio pouco conhecido, publicado em Bonn em 1876 sob o título de Ho

20 A associação entre afeição e thumos aparece também em Hist. anim. I 1 488b21: "outros animais são impulsivos, afetuosos e carinhosos (thumika kai philêtika kai thôpeutika), como os cachorros". 
thumos apud Aristotelem Platonemque. ${ }^{21}$ Neste trabalho, o erudito alemão define o thumos - tanto platônico como aristotélico - como uma vis naturalis que leva o homem a realizar sua própria natureza, portanto a preservar sua vida, e a se defender de todos os entraves internos e externos que se opõem a esta realização. ${ }^{22}$. Esta definição é suposta dar conta não somente das paixões de rivalidade, mas também da afeição. Com efeito, se o thumos é esta força que leva o homem a agir segundo sua própria natureza e se a amizade faz parte da natureza humana, então o thumos deve ser também esta força que leva os homens a se unir por amizade. ${ }^{23}$

A hipótese, assim formulada, é evidentemente um pouco simplista. Com efeito, se ela mostra a dependência da amizade do thumos em nome da realização da natureza humana, ela fica, todavia, um pouco vaga e não explica por que, por exemplo, o thumos não preside também os desejos físicos indispensáveis à nossa conservação, como a alimentação ou a reprodução. Desejos que, ao contrário, pertencem ao domínio da epithumia. Porém, a despeito de sua imprecisão, a tese de Meyer é interessante e chama a atenção sobre um aspecto importante: o natural positivo no homem.

Com efeito, seria melhor dizer que o thumos é a faculdade da alma que preside a "virtude natural", isto é, estas tendências não racionais, naturalmente positivas em si, da natureza humana, que são a condição necessária, embora não suficiente, da realização da virtude no sentido próprio. Por exemplo: a coragem natural inata, a tendência à amizade com os agentes bons, a reação imediata de cólera a uma injustiça. Estas tendências são todas naturalmente positivas e implicam já em si certa medida, o que não é o caso dos desejos sensuais, que em si são negativos, pois tendem à desmedida. 24

21 Este trabalho é citado por Aubonnet, p. 178 n. 15 e por R. Laurenti, em Aristotele, Politica, Bari Laterza, 1966, p. 337 n. 87 .

22 Cf . por ex. p. 6: Ho thumos est ea naturalis vis, qua quisque quatenus is ipse est, impellitur ut naturam ac vitam ipsi propriam omni ratione defendat.

23 Ibid.: Quodsi re vera ho thumos ea vis est, quae impellit ut secundum suam quisque propriam naturam agat, ho thumos debet esse, qui homines ad amicitias iungendas ducas.

24 O thumos, sendo eminentemente natural e entretendo sempre uma ligação com a razão, parece ser a parte ou a faculdade da alma mais apta a ter o papel da virtude natural. Se existe uma excelência (aretê) natural da faculdade desiderativa impulsiva que é o thumos, não parece haver, por outro lado, uma excelência similar no tocante à faculdade desiderativa irracional e sensual que é a epithumia. Podemos assim supor que não há virtude natural propriamente dita no tocante à epithumia e aos desejos sensuais, a não ser no sentido passivo e extrínseco de se deixar dominar pela razão. Se há uma virtude natural da sôphrosunê, não será no mesmo sentido em que há para a coragem. Sobre a "virtude natural" em Aristóteles, tomo a liberdade de assinalar meu estudo "Virtu' naturale e costituzione fisiológica: l'etica aristotelica è un 
Os limites da investigação de Meyer estão ligados à vontade de assimilar a todo custo, como indica, aliás, o título de seu ensaio, as noções de thumos de Platão e de Aristóteles. Esta assimilação resulta por vezes em conclusões desviantes e paradoxais, como a de atribuir a Aristóteles a tese que o thumos combate também os desejos sensuais ${ }^{25}$, quando em Aristóteles é somente a razão que está encarregada de dominar a epithumia, a qual não tem nenhum contato com o thumos. Porém, a despeito destes limites, este estudo tem o grande mérito de querer reconduzir a pluralidade de certos estados emocionais irracionais a um princípio comum, o thumos, e de mostrar também que o esquema de base das funções psicológicas fundamentais em Aristóteles é relativamente simples e "econômico", reduzindo-se essencialmente às três formas de desejo: racional, impulsivo e sensual. Aliás, a respeito das emoções de rivalidade, vimos que elas podem ser facilmente reconduzidas à emoção fundamental que é o desejo de superioridade (huperochê), assim como todas as formas de afeição dependem em última instância do amor de si (philautia).

\section{Conclusão}

Voltemos agora às questões postas no início desta investigação. Quanto à primeira, se há um ponto comum de origem para as paixões contraditórias, que provêm de um lado da amizade e, de outro, da rivalidade, a resposta é sem dúvida positiva: trata-se da faculdade impulsiva, o thumos. Aristóteles o diz explicitamente na passagem da Política que examinamos. O problema está, por outro lado, em compreender como se articulam estes dois estados emocionais contrários na faculdade impulsiva. Aristóteles nos diz somente que o sentimento de cólera é amplificado quando implica um sentimento de afeição prévio pelo sujeito em questão.

Quanto à segunda questão, se esta origem dos sentimentos de amizade e das paixões de rivalidade nos permite compreender melhor a noção aristotélica de amizade, parece-me que a resposta é igualmente positiva. A faculdade impulsiva, o thumos, é em última instância a salvaguarda da individualidade. Dele decorrem as emoções fundamentais que presidem respectivamente a rivalidade e a afeição, a saber: o desejo de superioridade e o amor de si. Em particular, vimos que a philautia determina ao mesmo tempo os parâmetros da rivalidade e os limites da amizade. Compreende-se 2005, p. 131-144.

25 Cf. p. 50. 
então que a ética aristotélica não é uma ética do altruísmo nem do egoísmo radicais. Trata-se antes de um individualismo moderado, do homem animal social, que contém analiticamente em sua própria natureza a amizade por seus semelhantes. As relações estreitas entre rivalidade e afeição sublinham de maneira evidente este aspecto fundamental da noção aristotélica de amizade.

\section{Referências Bibliográficas}

Aubenque, P. Logos et pathos. Pour une définition dialectique des passions (De anima, I, 1 et Rhétorique, II), in Corps et âme. Sur le De anima d'Aristote, G. Romeyer-Dherbey e C. Viano (eds.), Paris, 1996, p. 7-49.

Aubenque, P. Sur la définition aristotélicienne de la colère, Revue philosophique $(147,1957)$, p. 300-317.

Aubonnet, J.A. Aristote: Politique, Paris, 1960-86.

Gill, Ch. Is rivalry a virtue or a vice?, in D. Konstan e K. Rutter (eds.), Envy, Spite and Jealousy, Edinburgh University Press (Edinburgh Leventis Studies I) 2003, p. 29-51

Laurenti, R. em Aristotele, Politica, Bari 1966.

Meyer, P. Ho thumos apud Aristotelem Platonemque, Bonn 1876.

Pellegrin, P. Aristote: Les Politiques, Paris 1993.

Viano, C. Competitive emotions and the thumos in Aristotle's Rhetoric, in D. Konstan \& N. K. Rutter (eds.), Envy, Spite and Jealousy: The Rivalrous Emotions in ancient Greece, Edinburgh University Press (Edinburgh Leventis Studies I) 2003, p. 85-97.

Viano, C. Passions, désirs et plaisirs de rivalité chez Aristote, in G. Romeyer-Dherbey e G. Aubry (eds.), L'Excellence de la vie. Sur L'Ethique à Nicomaque et l'Ethique à Eudème d'Aristote, Paris, Vrin 2002, p. 237-252.

Viano, C. Virtu' naturale e costituzione fisiologica. l'etica aristotelica è un determinismo materialista?, in C. Natali- S. Maso (ed.), La catena delle cause. Determinismo e antideterminismo nel pensiero antico e in quello contemporaneo, Amsterdam, 2005, p. 131-144.

Wartelle, A. Lexique de la Rhétorique d'Aristote, Paris 1982.

[Tradução de Marco Zingano; revisão de Paulo Fernando Tadeu Ferreira] 